\title{
Literature Studies on Maintenance Management
}

\author{
Soesatijono Soesatijono ${ }^{a}$, Mahros Darsin ${ }^{b}$ \\ aPetra Christian University \\ ${ }^{b}$ Department of Mechanical Engineering, the University of Jember \\ e-mail: mahros.teknik@unej.ac.id
}

\begin{abstract}
The purpose of this paper is to review from early days until recent time the development of maintenance management methods from maintenance textbooks to give a glance view for researcher and practitioner where maintenance start until recent development and practical application of maintenance management. The methodology approach is by reviewing an early age maintenance management, maintenance management on eighties, maintenance management on nineties and recent maintenance management. Comparing and categorizing maintenance management methods along with time will increase knowledge how to choose the right maintenance for practical application. From this review it found that the paper also revealed from time to time, maintenance management adapt and improve to gain more sustainable maintenance, including the new shift of paradigm of maintenance itself. The originality and contribution of this research is that the paper contains many maintenance management methods from maintenance textbooks, maintenance management methods elaborated in an easy way. Therefore, the importance of maintenance management could be properly understood. For further study, the paper suggest that research needed to study or apply on methods found in this paper on practical application whether will give a proper result or just nice on theoretical only.
\end{abstract}

Keywords: maintenance; management; improvement; history of maintenance

\section{INTRODUCTION}

This paper will discuss about literature studies of maintenance management, start from the beginning to the recent development. Many argues that maintenance only needed by manufacturing industry, but in fact the philosophy of maintenance management could be applied in any aspect of industries. Reviewing development of maintenance management time to time will broaden knowledge on maintenance also give some idea what kind of maintenance concepts that suits to specific industries. Exploring maintenance management development just like exploring development of technology by humankind, the more technology been developed, maintenance management follows. Many maintenance books and textbook printed and circulated Organization of this paper will describe as follow:

a. History of maintenance, discuss about maintenance start form beginning to the recent development of maintenance

b. Types of maintenance, after discuss the history, start to discuss types of maintenance and its application on industrial environment

c. Recent development of maintenance, discuss further about recent development of maintenance management that commonly used in industrial company

d. Conclusion \& further study, conclude what have been elaborate on three sections above and suggestion for further study 


\section{History OF MAINTENANCE}

The official definition of maintenance is combination of all technical, administrative and managerial actions during the life cycle of an item intended to retain it in, or restore it to, a state in which it can perform the required function (BS-EN-13306, 2010), however, to reach this definition there was a process along with time.

History of maintenance and maintenance management starting when human find tools and equipment and move forward in line with innovation of equipment, machines, technology and system. The changes due to many factors, perhaps due to the complexity of the systems or due to the development of the technology and the research that done in this field (Moubray, 1997). Nowadays, maintenance management not only seen as separate part of production systems, but also seen as strategic element to achieve business success.

According to Moubray (1997) there are three generations of maintenance up to now. Up to the Second World War, the industries were not highly mechanised and the downtime in the production did not matter. Therefore, many owner / manager of company have not any desire to prevent equipment's failure. That was because the equipment was simple, no need in hurry to finish the order so that lead to no systematic maintenance was needed and the basic maintenance philosophy was to fix the problem when they occurred. Figure (1), illustrates the traditional thinking of failure occurrence which is the failure rate increase by the time

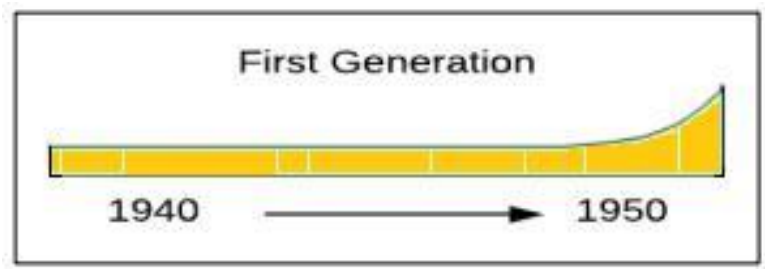

Figure 1. Traditional thinking of Failure occurrence, first generation (Moubray, 1997)

During and after the Second World War, manufacturing of equipment and machines changed rapidly. New technology implemented on different equipment \& machines and began to be complex and more sophisticated, in comparison to the old one (Moubray, 1997). New equipment, new machinery with new technology, increase the cost of equipment or machinery, so that increase concern from managers to increase reliability of the equipment. This not only because of cost of machinery but also cost of down time of machinery will suffer business objectives. That resulted in the birth of the preventive maintenance philosophy. The cost of increasing maintenance work led in turn to maintenance planning and control systems. Figure 2 illustrates the traditional thinking of failure occurrence in this generation.

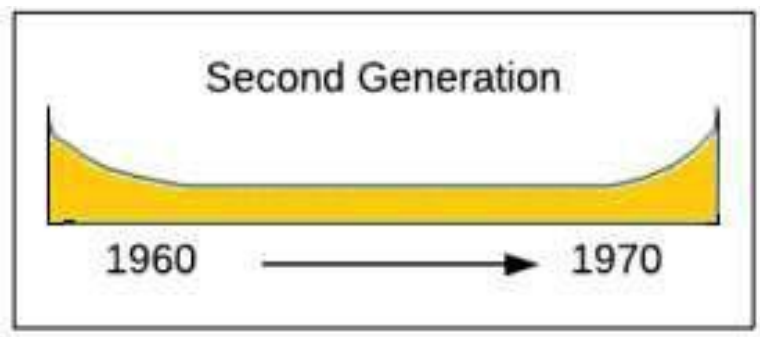

Figure 2. Traditional thinking of Failure occurrence, second generation (Moubray, 1997)

In third generation, the changes in industries have been gathered even greater momentum. It can be summarized in new expectations, new research and new 
techniques (Moubray, 1997). In 1960's and 1970's, the concept of just in time (JIT) manufacturing became in focus. That means, any stop of the production could interfere the operation of an entire facility. By other words, the downtime (planned or unplanned) has many effects on increasing operating costs, reducing output and affecting the customer service. Therefore, in this generation, the downtime is an issue that need detailed analyzing. The mechanization and automation of the facilities have also become as issues in this generation. Therefore, reliability and availability are issues as diverse as health care, data processing, and telecommunications (Moubray, 1997). Another issue is the quality standards that are arising rapidly. Some failures have serious safety and environment consequences. These types of failure must be prevented of mitigated. All these issues, increase the dependence on the integrity of the physical asset. In this generation, it became evident to the research and maintenance engineers that there are different failure patterns (Figure 3).

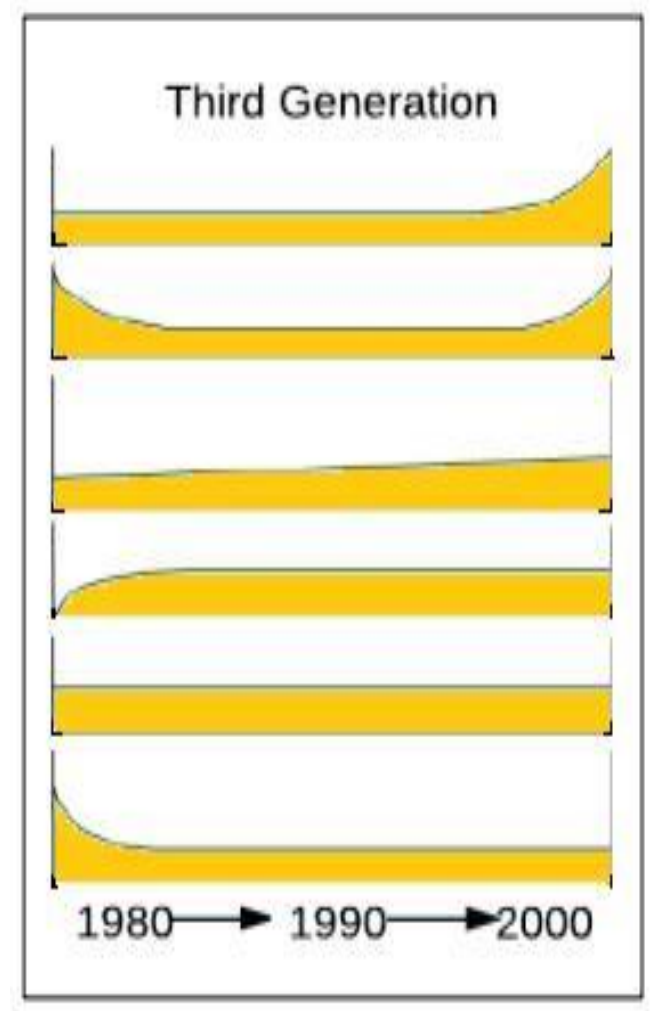

Figure 3. Failure Pattern (Moubray, 1997)

In this generation, back to Japan, Total Productive Maintenance (TPM) was developed by Seiichi Nakajima based on experience of the practical application of maintenance best practice in Japan between 1950 and 1970. This experience led to the recognition that a leadership mindset engaging front line teams in small group improvement activity is an essential element of effective operation. The outcome from his work was the application of the TPM process in 1971. One of the first companies to gain from this was Nippondenso, a company that created parts for Toyota. They became the first winner of the PM prize. An internationally accepted TPM benchmark developed by the JIPM Seiichi Nakajima is therefore regarded as the father of TPM. The classic TPM process he developed consisting of 5 principles was later enhanced by the JIPM to incorporate many of the lessons of Lean Manufacturing and is referred to as Company Wide TPM which consists of 8 principles/pillars.

According to Moubray (1997), during this generation, there are an amazing growth of maintenance concepts and techniques. The development includes: 
1. Decision support tools such as hazard studies, failure mode and effect analysis

2. New techniques such as condition monitoring

3. Designing equipment with must greater emphasis on reliability and maintainability

4. A major shift in organisation thinking towards participation, team working and flexibility

To sum up evolution of maintenance can be seen on Figure 4 made by Moubray (1997).

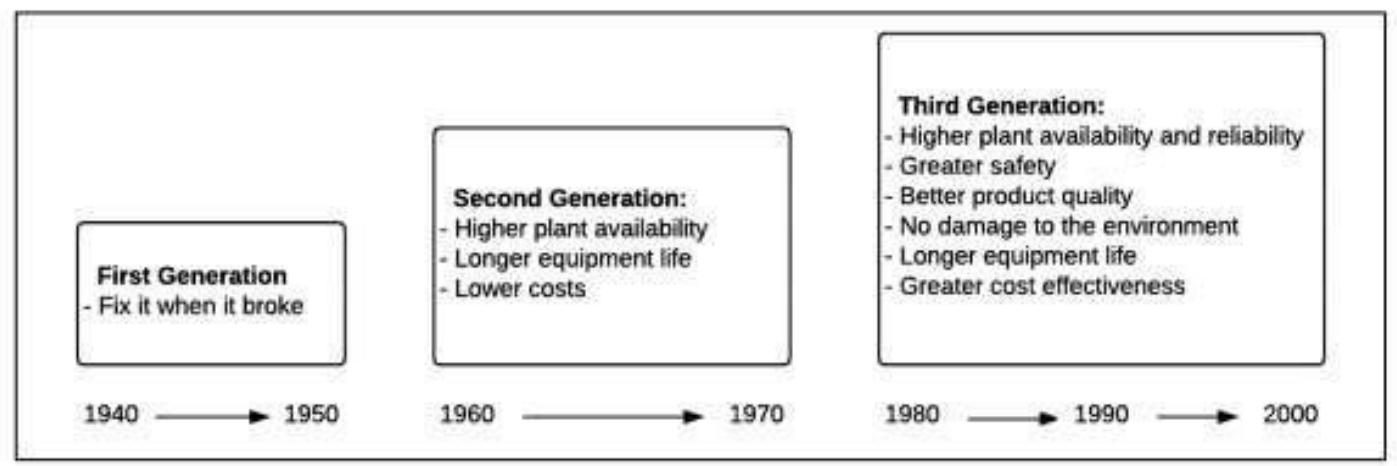

Figure 4. The Evolution of Maintenance (Moubray, 1997)

The greatest challenge facing maintenance personnel nowadays is not how to learn and applied new maintenance techniques rather than how to decide which maintenance techniques must be applied that most suitable to his/her organizations in which could maximize business objectives.

\section{TyPES OF MAINTENANCE Breakdown Maintenance}

Strategy for this maintenance is "fix it when it broke", so there is no maintenance until machine or component broken. Advantage of this maintenance are cheap and machine not over maintained. However, disadvantage of this maintenance are no preparation when machine broke, not knowing where to start to repair, tent to higher production loss, work in process defect and so on.

This type of maintenance could be appropriate implemented on machine that do not critical to production line / interruptible process or on simple machines/ simple equipment, have a number of machine redundant, cheaper to wait until broke that maintain regularly and have long MTTF (Mean Time to Failure).

\section{Planned Maintenance}

Planned maintenance tent to do maintenance before the machine broke or known as "fix it before brake" several types of planned maintenance will discuss here

\section{a) Preventive Maintenance}

Definition of preventive maintenance is maintenance carried out at predetermined intervals or according to prescribed criteria and intended to reduce the probability of failure or the degradation of the functioning of an item (BS-EN-13306-2010). On other words, preventive maintenance is a daily maintenance (cleaning, lubricating, oiling, tightening and inspection), targeting to retain the healthy condition of equipment and prevent failure through the prevention of deterioration, periodic inspection or equipment condition diagnosis, to measure deterioration.

\section{b) Predictive Maintenance}

Definition of predictive maintenance is condition based maintenance carried out following a forecast derived from repeated analysis or known characteristics and evaluation of the 
significant parameters of the degradation of the item (BS-EN-13306-2010). This is a method in which the service life of important part is predicted based on inspection or diagnosis, in order to use the parts to the limit of their service life. Compared to preventive maintenance, predictive maintenance is condition based maintenance. It manages trend values, by measuring and analyzing data about deterioration and employs a surveillance system, designed to monitor conditions through an on-line system.

\section{c) Corrective Maintenance}

Definition of corrective maintenance is maintenance carried out after fault recognition and intended to put an item into a state in which it can perform a required function (BS-EN13306-2010). It improves equipment and its components so that preventive maintenance can be carried out reliably. Equipment with design weakness must be redesigned to improve reliability or improving maintainability

\section{Productive Maintenance}

\section{a) Reliability-Centred Maintenance}

Moubray (1997) defines RCM as "a process used to determine the maintenance requirements of any physical asset in its operating context". The same author also defined it as "a process used to determine what must be done to ensure that any physical asset continues to do whatever its users want it to do in its present operating context".

Another definition of RCM is according to Regan (2012) which is "a zero-based, structured process used to identify the failure management strategies required to ensure an asset meets its mission requirements in its operational environment in the safest and cost effective manner". In this definition, there are three important terms:

Zero-Based. It means that failure modes and failure effects are written assuming that nothing is being done to prevent or predict the failure mode. That leads to failure consequences are assessed, and solutions are formulated without mentions to what is currently being done.

1. Failure Management Strategies. It means that RCM analysis process is carried out to identify the failure management strategies, not maintenance tasks.

2. Operational Environment. It means that when solutions for an asset are formulated, some different issues regarding the operational environment are considered.

Reliability-Centered Maintenance (RCM), identifies the functions of a system, equipment, which could be critical and then seeks to optimise their maintenance strategies. The most critical assets are those that are often likely to fail or those that have some hazard consequences in case failure (Regan, 2012). It is almost impossible to prevent all failure but it is possible to develop a maintenance strategy that could prevent some failures. The essence of RCM is to manage the consequences of the failure, not necessarily preventing them.

One of the most beneficial products of an RCM analysis is the identification of the best proactive maintenance tasks such as on-condition maintenance, scheduled restoration \& replacement, and scheduled discard tasks. With this maintenance tasks, possible failure modes and their consequences are identified while the function of the equipment is considered. The most effective techniques are then selected to improve the reliability of an asset.

\section{b) Integrated Condition Monitoring}

Integrated condition monitoring is the process of monitoring a parameter of condition in machinery (vibration, temperature etc.), in order to identify a significant change which is indicative of a developing fault. The use of condition monitoring allows maintenance to be scheduled, or other actions to be taken to prevent consequential damages and avoid its consequences. Condition monitoring has a unique benefit in that conditions that would shorten normal lifespan can be addressed before they develop into a major failure. 
Condition monitoring techniques are normally used on rotating equipment, auxiliary systems and other machinery (compressors, pumps, electric motors, internal combustion engines, presses). The following list includes the main condition monitoring techniques applied in the industrial and transportation sectors:

1. Vibration analysis and diagnostic

2. Lubricant analysis

3. Acoustic emission

4. Infrared thermography

5. Ultrasound

6. Motor condition monitoring and motor current signature analysis (MCSA)

7. Model-based voltage and current systems (MBVI systems)

\section{Total Productive Maintenance}

Total Productive Maintenance (TPM) is maintenance approach not only focusing on equipment but also focusing on team work and leadership. The purpose of TPM stated by Tajiri and Gotoh (1992) as follow:

1. The goal of TPM is to build a robust enterprise by maximizing production system efficiency (by overall effectiveness)

2. TPM addressed the entire system life cycle and build a concrete, shopfloor-based system to prevent all losses. It aims include elimination of all accidents, defect and breakdown

3. TPM involves all departments, from production to development, sales, and administration

4. Everyone participates in TPM from executive to shopfloor employees

5. TPM achieves zero losses through overlapping team activities.

The novelty of TPM is involving all employees to participate in maintenance. There are shifting paradigm and culture throughout company and breakdown hurdle among departments. TPM has an obvious measurement that cannot clearly stated by other maintenance type/models, which is Overall Equipment Effectiveness (OEE). With OEE, maintenance manager able to calculate qualitatively the progress of his/her maintenance programs, whether coming good or getting worse.

\section{Recent Development of Maintenance Management}

Maintenance management moved from only fixed it when broke become sophisticated maintenance models that enable systems to react on several conditions that endanger availability, quality, production targets and company objectives. Maintenance management cannot separated from enterprise policies. Amik Garg \& SG Deshmukh (2006) have 4 emerging concept of maintenance management as follow:

1. Neural Management Maintenance

2. Simulation Maintenance

3. Customized Maintenance Concept

4. Object Oriented Maintenance Management

Artificial Neural Networks (ANN) is connectionist systems are computing systems that are inspired by, but not identical to, biological neural networks that constitute animal brains. Such systems "learn" to perform tasks by considering examples, generally without being programmed with task-specific rules. Application of ANN in maintenance management will have superb pattern classification, matching and completion, trend prediction capability to generalize reliability, efficiency and fast respond. Polimac and Polimac (2001) state that maintenance methods applied at present should be combined in a comprehensive neural management maintenance systems, which would permanently monitor the system and suggest the most appropriate actions and strategies. 
Simulation Maintenance not much used in maintenance due to complexity of the system, however, with some assumption, simulation could be done such as what El Hayek et al. (2005) done on life cycle cost of complex aircraft engine. This type of maintenance will give high profitability to the company.

Customized maintenance concepts can be define as a set of different type of maintenance (breakdown maintenance, predictive maintenance, corrective maintenance) applied in one company specific for its machineries. Waeyenbergh and Pintelon (2002) highlighted that more and more companies are searching for a customized maintenance concepts. The framework described in this paper offers some guidelines to develop such a concept, and borrows some ideas from maintenance concepts described in literature. An important feature of the framework is that it allows to incorporate all information available in the company, ranging from experience of maintenance workers to data captured by modern Information and Communication Technology (ICT) means.

\section{Conclusion And Further Study}

Maintenance techniques especially maintenance management evolute in line with development and innovation on technology. Maintenance become increasingly important because the impact of breakdown decrease company profit. Firstly, maintenance address only to the hardware, further, maintenance including data base, software and advance technology to solve the problem, latest maintenance management using all sources, start from the hardware, machine itself, advance technology to help ease the problem, even now include to all personnel on manufacturing to do the trick so that could give high impact and help company to survive.

Many methods of maintenance management arose, but no generic maintenance management models that able to implement on each company. At least, it should be established a generic maintenance models for small enterprise, medium enterprise and large enterprise, from that models, developed to become customized to that specific enterprise by integrating with other functional departments such as production department, logistic department, quality management department and so on.

\section{REFERENCES}

1. Al Hainy, Haidar (2016), Reliability centered maintenance, different implementation approaches, Lulea University of Technology

2. BS-EN (2010). 13306: 2010-Maintenance Terminology. European Standard. European Committee for Standardization, Brussels. Standard

3. Ebeling, Charles E. (2010). An introduction to reliability and maintainability engineering. 2nd ed. Long Grove, III.: Waveland Press.

4. El Hayek, M., van Voorthuysen, E. and Kelly, DW (2005) Optimizing life cycle cost of complex machinery with rotable modules using simulation Journal of Quality in Maintenance Engineering, Vol 11 No. 4, pp 333-47

5. Gark, Amik and Deshmukh, SG (2006). Maintenance Management: literature review and directions: Journal of Quality in Maintenance Engineering, Vol 12 , No.3 pp 205236

6. Moubray, John (1997). Reliability-centred maintenance: [RCM II]. 2. ed. Oxford: Butterworth Heinemann.

7. Mills, SRW (2010). Vibration Monitoring \& Analysis Handbook. British Institute of Non-Destructive Testing.

8. Nowlan, S \& Heap, H (1978). Reliability Centered Maintenance: Declassified -best available data. National Technical Information Service. US.

9. Polimac, V and Polimac, J (2001) Assesment of present maintenance practises and future trends Proceedings Annual Reliability and Maintainability Symposium IEEE, pp 891-4

10. Regan, Nancy (2012). The RCM solution: a practical guide to starting and maintaining a successful RCM program. New York: Industrial Press, Inc. 
JEMMME (Journal of Energy, Mechanical, Material, and Manufacturing Engineering)

Vol. 6, No. 1, 2021 doi: 10.22219/jemmme.v6i1.12571

11. Tajiri, Masaji dan Gotoh, Fumio (1992), TPM Implementation, Japanese Approach, McGraw-Hill New York

12. The Japan Institute of Plant Maintenance (1992), TPM for Every Operator, Productivity Press, Portland, Oregon

13. Venkatesh, J http://www.plant-maintenance.com/articles/tpm intro.shtml

14. Waeyenbergh, G and Pintelon, L. (2002) A framework for maintenance concept development International Journal of Production Economics, Vol \& No.3 ,pp.299-313

15. https://en.wikipedia.org/wiki/Total productive maintenance

16. https://en.wikipedia.org/wiki/Condition monitoring 